\title{
Strategy Creation Procedures at Corporation in Indonesia: Concept vs Practice
}

\author{
Rapina Rapina, Johannes Buntoro Darmasetiawan, Rosalina O. Fuentes, Duarte Davinci Doloksaribu \\ and Recky Noviansyah
}

\begin{abstract}
Strategy will valuable when it is used as a managerial process for developing and sustaining the integrations between organizational goal, organizational resources, and the continuously changing market opportunity with an objective to shape and adjust organizational effort and products, so an organization can reach competitive advantage. This paper is written to contrast the strategy formulation process and the functions of strategy embedded in the formulation process in textbook theoretical side and in practical side in business organizations in Indonesia. This study uses a questionnaire to see respondents' responses. Majority of the 82 organizations participating in this study believe that they use the same strategy formulation process as the theory suggested and they also believe that they are utilizing the strategic functions embedded in the formulation process. The results of this study are expected to be able to give contribution to the business organizations when they are formulating their strategy, effort that they have to invest, and advantages that they can utilize by having a specific strategy formulation process. The well crafted and adjusted strategy to changes of the environment and internal factors will enable organizations more focus in reaching their long-term goal and adapting to uncontrollable changes.
\end{abstract}

Index Terms - Corporate Strategy, Evaluating Strategy, Executing Strategy, Strategy Creation.

\section{INTRODUCTION}

Every strategy with its clear vision will imply specificity in doing job [1]. Taking the analogy of baking cake to explain, doing a strategy is also an experiment. If we missed one single ingredient, the cake will fail to bake. In military understanding, strategy involves planning and briefing while preparing for a battle or campaign on a broad scale, and it is a responsibility of the general. While in the business world, "strategy" is commonly used to refer to a specific action that is taken to offset the actual or potential actions from competitors. In more basic understanding, this terminology states about the relationship with goal setting, exact goal formulation, and the selection of specific actions that are needed in the application of resources for achieving goals [2].

In congruence with the above statement, Fagel [3] states that a strategy is a plan or method that is used in giving efficient and effective directions in using resources as to fulfil the organization's goal. Strategy development can be seen as a logical process that considers thoroughly the organization's

Published on August 24, 2020.

Rapina Rapina, Maranatha Christian University, Indonesia.

(corresponding e-mail: rapinacen ${ }^{\circledR}$ yahoo.com)

Johannes Buntoro Darmasetiawan, Maranatha Christian University, Indonesia \& SAIDI Graduate School of Organization Development, Philippines.

(e-mail: jdarmasetiawan ${ }^{@}$ yahoo.com) strengths by using analytical techniques and evaluations to set a clear strategic direction with careful considerations. Usually strategy development is allocated as the responsibility of top management [4]. In line with the mentioned statement, Crainer and Dearlove [5] state that strategic formulation is seen as the exclusive domain from the executive management, while the formulated strategy will be executed by the middle management.

A strategy, even when considering the most creative ones, will not be valuable if it cannot be executed. Execution is the most important yet hardest part in a strategy. The key in effective strategy execution is in convincing all of the organization to unanimously support the existing strategy. Some obstacles that are faced by the organization when executing strategy are called silent killers, thus managers need to be careful in recognizing those obstacles [6]. Voehl and Harrington [7] state that problems in executing strategy that mainly faced by organizations have similarities with those that are faced by leaders in the world. In executing strategy, obstacles will not cease to exist and will always be hard to overcome. Even when planning a strategy is hard and challenging, leaders will always see the success in executing strategy as more problematic than strategy formulation yet important for organizational performance. Therefore, strategy needs to be communicated in a two-way communication process and using top to bottom approach Strategy is seen as a product that completes a planning process that involves all stakeholders including employees from the beginning. Strategy is like a map while the organizational values are like a compass that is linked with organizational culture. The organizational culture needs to be developed to strengthen values and sustain strategy. Strategy management is a process because it can be seen as a chain of continuous actions and not as event that can be left alone for a certain period of time only [8].

At some cases, though, the business environment that is faced by the organization can be different than the situation when the strategy was formulated. Depend on how significant the shift of business environment, the organization may require minor to major change of the formulated strategy to adapt with the shift of the business environment. The Covid19, for example, brings chaotic situation to the business environment. Organization needs to adjust their strategy to adapt with the Covid-19 attack. Infia Media Pratama, for

Rosalina O. Fuentes, SAIDI Graduate School of Organization Development, Philippines.

(e-mail: prosy.fuentes@gmail.com).

Duarte Davinci Doloksaribu, Maranatha Christian University, Indonesia.

(e-mail: duartedavinci@gmail.com).

Recky Noviansyah, Maranatha Christian University, Indonesia.

(e-mail: reckynov@gmail.com) 
example, formulate a specific strategy to cope with current crises [9]. Tiket.com is shifting the strategy from sales to customer handling services [10]. AirAsia Indonesia has also made a major move by focusing more on their side business [11].

Based on the above explanation, there are two questions that can be raised at this research. What are the visible differences between the THEORY \& PRACTICE at business organizations in Indonesia when formulating a strategy? And is it a necessity to take advantage of the strategic functions embedded in the strategy formulation process in business organizations in Indonesia?

\section{LITERATURE REVIEW}

\section{A. Theory Of Strategy}

Management scholars give different definition what is a strategy. A strategy always involves a process in setting the organization's future direction and executing decision in achieving organization's short-term and long-term goals [12]. The next definitions states that strategy is the basic finding of organization's long-term goals and target by adopting action programs and allocating needed resources to carry out set goals [13]. Stephens and Martin [14] state that strategy is an action that managers take to attain one or more of the organization's goals. Although the word by word definition itself is different, there are common understandings about what is a strategy. A strategy always involves future direction. A strategy always discusses how to reach the future destination (goal).

The definition of strategy gives a general function of strategy. To be able to utilize a strategy effectively, management scholars design what are the processes to formulate a strategy. Each of the well thought process that formulates a strategy is believed to bring another specific function of the strategy. $\mathrm{n}$ other words, different formulation processes will bring different specific functions, in addition to the general function. It is a question, though, practitioners use all the function of strategy when they lead an organization

\section{B. Strategy Formulation Process As A Research Variable}

To be able utilize a strategy A strategy cannot be formulated by an instant effort. It involves several well thought process. Different management scholar proposes different processes. Trivedi [15] proposes six processes, they are: setting organizations' objectives, evaluating the organizational environment, setting quantitative targets, aiming in context with the divisional plans, performance analysis, and choice of strategy. Annarelli et al [16] also propose six processes, there are: study and definition of the organizational context, study and definition of the strategic mission, study and definition of strategic objectives, study and definition of competitive strategy, implementation of developed strategies, and analysis and evaluation of progresses and results performed. On the other hand, Thompson et al [17] propose five processes. For this research study, the authors will use the formulation processes proposed by Arthur A Thompson \& Thompson [17], whose textbook is also used to teach Strategic Management class at Maranatha Christian University. Thompson et al [17] state there are five interrelated steps in setting and executing strategy, those steps are as follows:

Step 1: Developing strategic vision that maps out the organization's long term directions, mission statement which depicts organization's direction, and a set of core values to guide the achievement of vision of mission.

A vision and a mission, which are the founder's or top management's inspirations about future organization shape and how the organization will give benefit to the stake holders, give a picture about where will the organization move. It is a process of describing the dream into short sentences. This process, therefore, will require a deep thought and internal search of what the organization look like and contribute in the future.

Step 2: Setting objectives to measure organization's performance and tracking organization's progress in moving towards the set long-term directions.

Setting objectives mean to make the long term dream to be more concrete and easier to be understood. The dream of destination should have a clearer and more detailed explanation. Some numbers should also be inserted to make the dream become more concrete. Setting objectives mean also dividing the journey toward reaching the long term dream (goal) into several milestones of performance targets. Each milestone indicates the targeted performance or contribution that should be achieved for a certain period of time. Milestones with longer term period, therefore, should be broken down into shorter term milestones, so that the organization members do not lose tract. This is a realistic process. The milestone has to be achieved realistically, not a dream. This process is recommended to involve will a group of trusted and experienced people who are willing to put an effort to collect, interpret, and extrapolate data. The capability of reaching Vision - Mission can be predicted by the capability of reaching these milestones (shorter and longer term goals).

Step 3: Setting strategy in line with management's road map so that it can sustain organization in achieving its goals.

Setting strategy means developing a road map of how to reach Vision - Mission and long term goal with shorter term goals as the check points to ensure the journey will be on track. Setting a strategy gives also an organization an opportunity to create their own unique organization shape and distinguish the organization from its competitors. Not to forget, organization also needs to consider the influence of external factors and the presence of internal factors. Their presence will give an effect to the effectiveness of the effort to meet shorter and longer term goals. Their presence, therefore, need to be consider when a road map is being developed. Since this process is a combination of art, knowledge, and experience, involving trusted people with competencies and commitment will help crafting a road map that considers all necessary factors.

Step 4: Executing chosen strategy efficiently and effectively.

A strategy is not a map or inspiring words to be hung on the wall. A strategy without execution will be useless. This process focuses on how to implement written plan into reality. Well crafted skills such as: teamwork, negotiations, perseverance and good timing are needed to execute what is written on paper into actions. The turbulent business 
environment and dynamic internal factors offer distraction. Therefore, organization members need to have consistency in following the road map and in looking for ways of how to implement strategy successfully. Often the failure of a strategy is not caused by the poorly developed strategy, but on the strategy implementation process [18]. Continuous communication (in the form of discussion and receiving feedback) with the people who will execute the strategy is advisable, so that it will not lead to the wrong direction [15] [16], [17].

Step 5: Monitoring developments, evaluating performance, and initiating corrective adjustments in vision, mission, goals, strategy or organization's approach in strategy executions as there are actual experiences, changing conditions, new ideas and new opportunities.

This process compares the actual performance with the target. This process gives an opportunity to review a strategy and strategy implementation process run smoothly or not. If not, then a careful evaluation needs to be done to revise the strategy development process. One by one process needs to be carefully evaluated. Perhaps the Vision-Mission is not clearly articulated, objectives are not realistic, strategy is not well crafted, external and internal factors make strategy worn out, or strategy is not well implemented.

\section{The Function Embedded In Research Variable}

While the strategy formulation process becomes the research variable, each process that formulate a strategy becomes a dimension of the research variable and is believed to bring a specific function of the strategy.

1. Developing Vision - Mission: Since vision and mission is the dream of the founder or top management in the form of short sentences, organization future shape can be predicted. Developing vision - mission, therefore has a function to serve as a concept route toward reaching the dream of top management [19]. This process describes where the organization will move to.

2. Setting Objectives: This process set long term targets and break down the long term goal into shorter term goals. It can be easily understood that achieving the goals is a prerequisite to achieving the vision - mission. This process, therefore, helps the organization members to understand what is their destination and focus on walking toward the direction. This process also breaks down the journey toward reaching the long term goal into milestones. Shorter term goals are designed, so that by achieving the shorter goal, goal term goal will be automatically achieved.

3. Crafting Strategy: This process develops a road map to achieve the dreamed vision - mission and long term goal with shorter term goals as check points to ensure the journey will be on track. The process of crafting strategy, therefore, helps an organization to become unique and differentiate from its competitors [19]. This process also acknowledges the influence of external factors and the impact of internal factors. These external factors and internal factors will be taken into account and matched to better develop the road map [19].

4. Executing Strategy: This process focuses on how to implement written plan into reality. Distractions along the way of strategy implementation can make the organizations take a short cut and end up at the wrong direction. Therefore, having a strategy and put an effort of implementing it, despite some distractions, will help organization with more stable focus [19].

5. Monitoring and Evaluating Strategy: This process compares the actual performance with the target. This process helps giving feedback on how effective is the strategy. If not effective, an evaluation of the whole strategy development process needs to be evaluated and some adjustments need to be done.

The strategy formulation process is the research variable. Each process will become a dimension of the research variable and provide a function of the strategy. Table 1 summarizes will pair the dimension of the strategy formulation process with strategy function.

TABLE I: THE EMBEDDED FUNCTIONS OF STRATEGY IN THE STRATEGY FORMULATION PROCESS

Developing Vision - Mission [Process] serves as a concept route
toward reaching the dream of top management [Function], therefore
this process requires deep thought
Setting Objective [Process] helps the organization to focus on the
future [Function], therefore this process requires a group of people put
an effort to collect and interpret data
Setting Objective [Process] serves as a reference for setting shorter
term goals [Function], therefore this process requires a group of people
put an effort to collect and interpret data
Crafting Strategy [Process] helps distinguishing an organization from
others [Function], therefore this process requires discussion with
trusted people, deep thought, and still be in line with Vision - Mission
Crafting Strategy [Process] helps matching external circumstances to
internal resources and competitive capabilities [Function], therefore
this process needs considering external factors faced by the
organization and internal factors inside the organization
Executing Strategy [Process] helps an organization to cruise with a
map so that the organization can have more stable focus
Monitoring and Evaluating Strategy [Process] helps giving feedback
on how effective is the strategy

\section{Methodology}

The research method that is used is mainly a survey by collecting information from people that act as the sources of information so that this paper can show a descriptive figure rather than explaining in words related with knowledge, behavior and attitude. Respondent in this research is the top management from various organizations in Indonesia. The reason for choosing top management as respondent is because they are the people that involve dominantly in organization's strategy formulation. They also have the responsibility in directing actions that help the formulated strategy planning put into actions.

Table 2 shows the information of strategy formulation process that will be collected from the questionnaire. The questionnaire will collect information from respondents if strategy formulation processes at textbook are available at their organization. Several confirmation statements will accompany statements of strategy formulation process to confirm if respondents really have the process and put an effort to craft each process. For example, majority respondents who claim they have a particular process, but respond that they do not put an effort of crafting that particular process will raise a question mark. Table 3 shows information that will be collected by the questionnaire about the function of strategy frequently used in organizations in Indonesia from respondents. A pair of statements (not a single 
statement) will always be asked for each function. This is to check if respondents are consistent or not. If majority respondents are inconsistent, a follow up questionnaire will be distributed for that particular pair of statement to the majority inconsistent respondents.

TABLE II: QUESTIONNAIRE FOR THE OPERATIONAL VARIABLE (THE STRATEGY FORMULATION PROCESS)

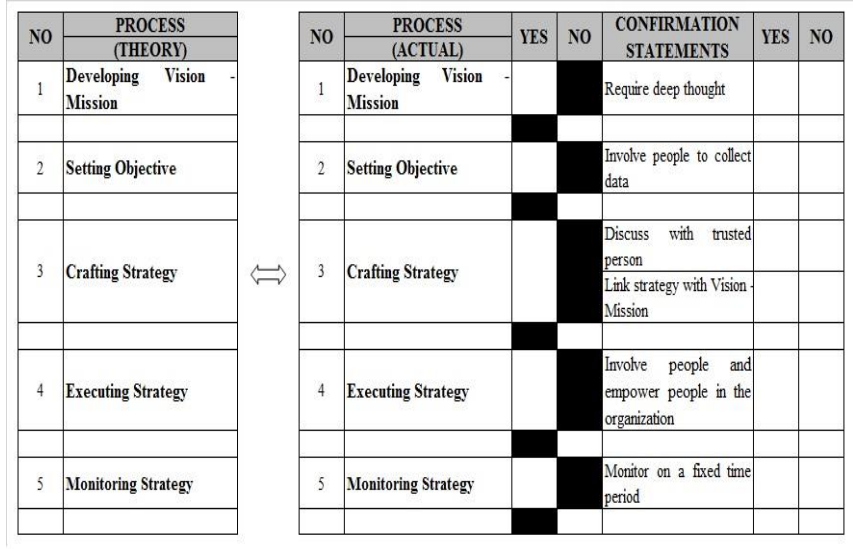

TABLE III: QUESTIONNAIRE FOR THE OPERATIONAL VARIABLE (THE STRATEGY FORMULATION PROCESS)

\begin{tabular}{|c|c|c|c|}
\hline FUNCTION & STATEMENT & YES & No \\
\hline Developing Vision - Mission: & $\begin{array}{l}\text { When a strategy needs to be changed, the change does not need to } \\
\text { consider organization's Vision and Mission }\end{array}$ & & \\
\hline $\begin{array}{l}\text { Serves as a concept route toward } \\
\text { reaching the dream of top }\end{array}$ & $\begin{array}{l}\text { When a strategy needs to be changed, organization's Vision and Mission } \\
\text { need to be revisited to align with the new strategy }\end{array}$ & & \\
\hline Setting Objectives: & $\begin{array}{l}\text { When a strategy needs to be changed, the change does not need to } \\
\text { consider organization's long-term goal (objective) }\end{array}$ & & \\
\hline $\begin{array}{l}\text { Helps the organization to focus on } \\
\text { the future }\end{array}$ & $\begin{array}{l}\text { When a strategy needs to be changed, the organization's long-term goal } \\
\text { (objective) needs to be changed to follow new strategy }\end{array}$ & & \\
\hline Setting Objectives: & $\begin{array}{l}\text { Short-term goal needs to be reviewed regularly so that strategy can nun } \\
\text { effectively }\end{array}$ & & \\
\hline $\begin{array}{l}\text { Serves as a reference for setting } \\
\text { shorter term goals }\end{array}$ & $\begin{array}{l}\text { When short-term goal is not met, then priority should be put more on } \\
\text { reviewing strategy implementation method rather than adjusting the } \\
\text { strategy }\end{array}$ & & \\
\hline Crafting Strategy: & $\begin{array}{l}\text { A strategy is created so that my organization becomes unique and } \\
\text { different from other organizations }\end{array}$ & & \\
\hline $\begin{array}{l}\text { Helps distinguishing an organization } \\
\text { from others }\end{array}$ & $\begin{array}{l}\text { The color and shape of organization will come naturally and does not } \\
\text { have correlation with strategy }\end{array}$ & & \\
\hline Crafting Strategy: & $\begin{array}{l}\text { When a change in external factor exists, then a strategy needs to be } \\
\text { changed }\end{array}$ & & \\
\hline $\begin{array}{l}\text { Helps matching external } \\
\text { circumstances to internal resources }\end{array}$ & $\begin{array}{l}\text { Even when there is no change in external and internal factors, a strategy } \\
\text { needs to be renewed regularly }\end{array}$ & & \\
\hline Executing Strategy: & $\begin{array}{l}\text { Strategy will guide organization more consistently towards the set Vision } \\
\text { and Mission }\end{array}$ & & \\
\hline $\begin{array}{l}\text { Helps an organization to cruise with } \\
\text { a map so that the organization can }\end{array}$ & $\begin{array}{l}\text { Running an organizational needs high flexibility, pop in creativity, and } \\
\text { impromptu decision. }\end{array}$ & & \\
\hline Monitoring Strategy: & The effectiveness of strategy need to be reviewed regularly & & \\
\hline $\begin{array}{l}\text { Helps giving feedback on how } \\
\text { effective is the strategy }\end{array}$ & Well thought strategy does not need to be monitored regularly & & \\
\hline
\end{tabular}

This survey research uses descriptive research methods. Descriptive research is merely describing a situation or event. This study does not seek or explain relationships, do not test hypotheses or make predictions. Data characteristics are obtained by measuring central tendency or size of distribution. This research is not intended to test certain hypotheses, but only describe "as is" a variable, symptom or condition.

The population in this study is the top management of various organizations in Indonesia whose numbers are unknown and can be said to be in the infinite category. Infinite population is population that has a data source which the limits cannot be determined quantitatively. The sampling technique in this study uses non-probability techniques namely incidental sampling technique, means the sampling technique is based on coincidence, that anyone by chance meets with researchers can be used as a sample, when people who happen to be found it suitable as a source of data. According to Roscoe in Sekaran and Bougie [20], a good sample size in this study was more than 30 and less than 500 . So in this study, the sample size used was not less than 30 respondents.

\section{FINDINGS AND ARGUMENT}

\section{A. The Survey Result}

There are 110 questionnaires distributed, but only 82 respondents fill the questionnaire. Based on the Ministry of Industry of Indonesia (Republic of Indonesia Minister of Industry Regulation Number 64 / M-IND / PER / 7/2016), the 82 organizations can be classified into four classification: micro (less than 5 organization members), small (5 to 19 organization members), medium (20 to 99 organization members), and big (more than 99 organization members). There are 50 organizations that are classified as micro, 14 organizations classified as small, 8 organizations classified as medium, and 10 organizations classified as big. Table 4, Table 5, Table 6, Table 7, and Table 8 summarize the survey result of for each strategy formulation process. The Tables not only show the result (in term of number of organizations and percentage of organizations with an affirmation), but also show the result for every organization size category. The non-italic printed part of the table indicates the statements of the strategy formulation process. While the italic printed part of the table indicates the statements of the function of strategy.

\section{B. Descriptive Statistics}

\section{Developing Vision-Mission}

Table 4 shows the first process: developing Vision Mission. There is a majority number (75 organizations or $91.5 \%$ ) of the 82 organizations that participate in the survey believe that Developing Vision - Mission is part of their strategy formulation process. Breaking down this result, micro organizations give $90 \%$, small organizations $92.9 \%$, medium organizations give $100 \%$, and big organizations give $90 \%$.

A smaller majority number (61 organizations or $74.4 \%$ ) of the 82 organizations support statement Nr. 2 at Table 4, which indicates that developing Vision - Mission should be taken seriously, therefore, this step needs deep thought to formulate. Breaking down this result, micro organizations give $74.4 \%$, small organizations give $72.0 \%$, medium organizations give $85.7 \%$, and big organizations give $70.0 \%$.

Statement Nr. 13 at Table 4 indicates that when a strategy needs to be changed, the change does not need to consider organization's Vision and Mission. This is an incorrect statement. A correct statement should indicate that a strategy is a path toward reaching Vision - Mission. In other words, when there is a change in strategy, senior management should ensure that the new strategy will still serve as a path toward reaching Vision - Mission. Hence, there is always a link between strategy and Vision - Mission. A majority number (59 organizations or $71.9 \%$ ) disagree the change of a strategy does not need to consider the existence of Vision - Mission. Breaking down this result, micro organizations give $68.0 \%$, 
small organizations give $85.7 \%$, medium organizations give $62.5 \%$, and big organizations give $80.0 \%$ to disagree with the statement. Statement Nr. 14 is to reconfirm statement Nr. 13.

Again, a majority number (57 organizations or $69.5 \%$ ) show a consistency by disagreeing with the statement. In other words, a change of strategy should always revisit Vision - Mission so that the new strategy and Vision - Mission will align one another. Breaking down this result, micro organizations give $68.0 \%$, small organizations give $78.6 \%$, medium organizations give $50.0 \%$, and big organizations give $80.0 \%$. Surprisingly medium organizations give an ambiguous answer at this statement. Overall, this means majority of respondents include Vision - Mission as a strategy formulation process and understand the utilization of having Vision - Mission in the process.

TABLE IV: SETTING OBJECTIVE

\begin{tabular}{|c|c|c|c|c|c|c|c|c|c|c|c|c|c|c|c|c|c|c|c|c|c|}
\hline \multirow{3}{*}{ No } & \multirow{3}{*}{ Statement } & \multicolumn{4}{|c|}{ TOTAL } & \multicolumn{4}{|c|}{ MICRO } & \multicolumn{4}{|c|}{ SMALL } & \multicolumn{4}{|c|}{ MEDIUM } & \multicolumn{4}{|c|}{ BIG } \\
\hline & & \multicolumn{2}{|c|}{ YES } & \multicolumn{2}{|c|}{ No } & \multicolumn{2}{|c|}{ YES } & \multicolumn{2}{|c|}{ No } & \multicolumn{2}{|c|}{ YES } & \multicolumn{2}{|c|}{ No } & \multicolumn{2}{|c|}{ YES } & \multicolumn{2}{|c|}{ No } & \multicolumn{2}{|c|}{ YES } & \multicolumn{2}{|c|}{ No } \\
\hline & & $\mathbf{F}$ & $\%$ & $\mathbf{F}$ & $\%$ & $\mathbf{F}$ & $\%$ & $\mathbf{F}$ & $\%$ & $\mathbf{F}$ & $\%$ & $\mathbf{F}$ & $\%$ & $\mathbf{F}$ & $\%$ & $\mathbf{F}$ & $\%$ & $\mathbf{F}$ & $\%$ & $\mathbf{F}$ & $\%$ \\
\hline 1 & $\begin{array}{l}\text { Do you have the process of developing } \\
\text { Vision - Mission in your organization? }\end{array}$ & 75 & 91.5 & 7 & 8.5 & 45 & 90.0 & 5 & 10.0 & 13 & 92.9 & 1 & 7.1 & 8 & 100 & 0 & 0.0 & 9 & 90.0 & 1 & 10.0 \\
\hline 2 & $\begin{array}{l}\text { Developing vision-mission requires deep } \\
\text { thought }\end{array}$ & 61 & 74.4 & 21 & 25.6 & 36 & 72.0 & 14 & 28.0 & 12 & 85.7 & 2 & 14.3 & 6 & 75.0 & 2 & 25.0 & 7 & 70.0 & 3 & 30.0 \\
\hline 13 & $\begin{array}{l}\text { When a strategy needs to be changed, the } \\
\text { change does not need to consider } \\
\text { organization's Vision and Mission }\end{array}$ & 23 & 28.1 & 59 & 71.9 & 16 & 32.0 & 34 & 68.0 & 2 & 14.3 & 12 & 85.7 & 3 & 37.5 & 5 & 62.5 & 2 & 20.0 & 8 & 80.0 \\
\hline 14 & $\begin{array}{l}\text { When a strategy needs to be changed, } \\
\text { organization's Vision and Mission need } \\
\text { to be revisited to align with the new } \\
\text { strategy }\end{array}$ & 25 & 30.5 & 57 & 69.5 & 16 & 32.0 & 34 & 68.0 & 3 & 21.4 & 11 & 78.6 & 4 & 50.0 & 4 & 50.0 & 2 & 20.0 & 8 & 80.0 \\
\hline
\end{tabular}

TABLE V: DEVELOPING VISION - MISSION

\begin{tabular}{|c|c|c|c|c|c|c|c|c|c|c|c|c|c|c|c|c|c|c|c|c|c|}
\hline \multirow{3}{*}{ No } & \multirow{3}{*}{ Statement } & \multicolumn{4}{|c|}{ TOTAL } & \multicolumn{4}{|c|}{ MICRO } & \multicolumn{4}{|c|}{ SMALL } & \multicolumn{4}{|c|}{ MEDIUM } & \multicolumn{4}{|c|}{ BIG } \\
\hline & & \multicolumn{2}{|c|}{ YES } & \multicolumn{2}{|c|}{ No } & \multicolumn{2}{|c|}{ YES } & \multicolumn{2}{|c|}{ No } & \multicolumn{2}{|c|}{ YES } & \multicolumn{2}{|c|}{ No } & \multicolumn{2}{|c|}{ YES } & \multicolumn{2}{|c|}{ no } & \multicolumn{2}{|c|}{ YES } & \multicolumn{2}{|c|}{ No } \\
\hline & & $\mathbf{F}$ & $\%$ & $\mathbf{F}$ & $\%$ & $\mathbf{F}$ & $\%$ & $\mathbf{F}$ & $\%$ & $\mathbf{F}$ & $\%$ & $\mathbf{F}$ & $\%$ & $\mathbf{F}$ & $\%$ & $\mathbf{F}$ & $\%$ & $\mathbf{F}$ & $\%$ & $\mathbf{F}$ & $\%$ \\
\hline 3 & $\begin{array}{l}\text { Do you have the process of Setting } \\
\text { Objective in your organization? }\end{array}$ & 79 & 96.3 & 3 & 3.7 & 48 & 96.0 & 2 & 4.0 & 14 & 100 & 0 & 0.0 & 8 & 100 & 0 & 0.0 & 9 & 90.0 & 1 & 10.0 \\
\hline 4 & $\begin{array}{l}\text { Setting objective requires a group of } \\
\text { people put an effort to collect and } \\
\text { interpret data }\end{array}$ & 66 & 80.5 & 16 & 19.5 & 39 & 78.0 & 11 & 22.0 & 12 & 85.7 & 2 & 14.3 & 7 & 87.5 & 1 & 12.5 & 8 & 80.0 & 2 & 20.0 \\
\hline 5 & $\begin{array}{l}\text { Setting objective requires putting an } \\
\text { effort to collect and interpret data } \\
\text { without involving a group on people }\end{array}$ & 29 & 35.4 & 53 & 64.6 & 20 & 40.0 & 30 & 60.0 & 5 & 35.7 & 9 & 64.3 & 3 & 37.5 & 5 & 62.5 & 1 & 10.0 & 9 & 90.0 \\
\hline 15 & $\begin{array}{l}\text { When a strategy needs to be changed, } \\
\text { the change does not need to consider } \\
\text { organization's long-term goal } \\
\text { (objective) }\end{array}$ & 7 & 8.5 & 75 & 91.5 & 6 & 12.0 & 44 & 88.0 & 0 & 0.0 & 14 & 100 & 0 & 0.0 & 8 & 100 & 1 & 10.0 & 9 & 90.0 \\
\hline 16 & $\begin{array}{l}\text { When a strategy needs to be changed } \\
\text { the organization's long-term goal } \\
\text { (objective) needs to be changed to } \\
\text { follow new strategy }\end{array}$ & 44 & 53.7 & 38 & 46.3 & 25 & 50.0 & 25 & 50.0 & 7 & 50.0 & 7 & 50.0 & 6 & 75.0 & 2 & 25.0 & 6 & 60.0 & 4 & 40.0 \\
\hline 17 & $\begin{array}{l}\text { Short-term goal needs to be reviewed } \\
\text { regularly so that the strategy can be } \\
\text { adjusted accordingly }\end{array}$ & 77 & 93.9 & 5 & 6.1 & 49 & 98.0 & 1 & 2.0 & 13 & 92.9 & 1 & 7.1 & 7 & 87.5 & 1 & 12.5 & 8 & 80.0 & 2 & 20.0 \\
\hline 18 & $\begin{array}{l}\text { When short-term goal is not met, then } \\
\text { priority should be put more on } \\
\text { reviewing strategy implementation } \\
\text { method rather than adjusting the } \\
\text { strategy }\end{array}$ & 62 & 75.6 & 20 & 24.4 & 36 & 72.0 & 14 & 28.0 & 12 & 85.7 & 2 & 14.3 & 6 & 75.0 & 2 & 25.0 & 8 & 80.0 & 2 & 20.0 \\
\hline
\end{tabular}

TABLE VI: CRAFTING STRATEGY

\begin{tabular}{|c|c|c|c|c|c|c|c|c|c|c|c|c|c|c|c|c|c|c|c|c|c|}
\hline \multirow{3}{*}{ No } & \multirow{3}{*}{ Statement } & \multicolumn{4}{|c|}{ TOTAL } & \multicolumn{4}{|c|}{ MICRO } & \multicolumn{4}{|c|}{ SMALL } & \multicolumn{4}{|c|}{ MEDIUM } & \multicolumn{4}{|c|}{ BIG } \\
\hline & & \multicolumn{2}{|c|}{ YES } & \multicolumn{2}{|c|}{ No } & \multicolumn{2}{|c|}{ YES } & \multicolumn{2}{|c|}{ No } & \multicolumn{2}{|c|}{ YES } & \multicolumn{2}{|c|}{ No } & \multicolumn{2}{|c|}{ YES } & \multicolumn{2}{|c|}{ No } & \multicolumn{2}{|c|}{ YES } & \multicolumn{2}{|c|}{ No } \\
\hline & & $\mathbf{F}$ & $\%$ & $\mathbf{F}$ & $\%$ & $\mathbf{F}$ & $\%$ & $\mathbf{F}$ & $\%$ & $\mathbf{F}$ & $\%$ & $\mathbf{F}$ & $\%$ & $\mathbf{F}$ & $\%$ & $\mathbf{F}$ & $\%$ & $\mathbf{F}$ & $\%$ & $\mathbf{F}$ & $\%$ \\
\hline 6 & $\begin{array}{l}\text { Do you have the process of Crafting } \\
\text { strategy in your organization? }\end{array}$ & 80 & 97.6 & 2 & 2.4 & 48 & 96.0 & 2 & 4.0 & 14 & 100 & 0 & 0.0 & 8 & 100 & 0 & 0.0 & 10 & 100 & 0 & 0.0 \\
\hline 7 & $\begin{array}{l}\text { Crafting strategy requires discussion with } \\
\text { trusted people, deep thought }\end{array}$ & 78 & 95.1 & 4 & 4.9 & 46 & 92.0 & 4 & 8.0 & 14 & 100 & 0 & 0.0 & 8 & 100 & 0 & 0.0 & 10 & 100 & 0 & 0.0 \\
\hline 8 & $\begin{array}{l}\text { Crafting strategy needs to be in line with } \\
\text { Vision-Mission }\end{array}$ & 71 & 86.6 & 11 & 13.4 & 47 & 94.0 & 3 & 6.0 & 13 & 92.9 & 1 & 7.1 & 8 & 100 & 0 & 0.0 & 10 & 100 & 0 & 0.0 \\
\hline 19 & $\begin{array}{l}\text { A strategy is created so that my } \\
\text { organization becomes unique and } \\
\text { different from other organizations }\end{array}$ & 70 & 85.4 & 12 & 14.6 & 44 & 88.0 & 6 & 12.0 & 12 & 85.7 & 2 & 14.3 & 7 & 87.5 & 1 & 12.5 & 7 & 70.0 & 3 & 30.0 \\
\hline 20 & $\begin{array}{l}\text { The colour and shape of organization } \\
\text { will come naturally and does not have } \\
\text { correlation with strategy }\end{array}$ & 30 & 36.6 & 52 & 63.4 & 23 & 46.0 & 27 & 54.0 & 3 & 21.4 & 11 & 78.6 & 3 & 37.5 & 5 & 62.5 & 1 & 10.0 & 9 & 90.0 \\
\hline 21 & $\begin{array}{l}\text { When a change in external factor exists, } \\
\text { then a strategy needs to be changed }\end{array}$ & 60 & 73.2 & 22 & 26.8 & 35 & 70.0 & 15 & 30.0 & 11 & 78.6 & 3 & 21.4 & 5 & 62.5 & 3 & 37.5 & 9 & 90.0 & 1 & 10.0 \\
\hline 22 & $\begin{array}{l}\text { Even when there is no change in external } \\
\text { and internal factors, a strategy needs to } \\
\text { be renew regularly }\end{array}$ & 62 & 75.6 & 20 & 24.4 & 38 & 76.0 & 12 & 24.0 & 10 & 71.4 & 4 & 28.6 & 6 & 75.0 & 2 & 25.0 & 8 & 80.0 & 2 & 20.0 \\
\hline
\end{tabular}

\section{Setting Objective}

Table 5 shows the result of the second process: setting objectives. There is a majority number (79 organizations or $96.3 \%$ ) of the 82 organizations that participate in the survey believe that Setting Objective should be part of their strategy 
formulation process. Breaking down this result, micro organizations give 96\%, small organizations give 100\%, medium organizations give $100 \%$, and big organizations give $90 \%$.

Majority respondents (66 organizations or 80.5\%) agree with statement Nr. 4 at Table 5. They believe that this is an important process, so that they you involve a group of people and put an effort to collect and interpret data in order to be able to set a meaningful objective. Breaking down this result, micro organizations give $78.0 \%$, small organizations give $85.7 \%$, medium organizations give $87.5 \%$, while big organizations give $80.0 \%$. On the other hand, majority of respondents (53 organization or $64.6 \%$ ) show consistency by disagreeing statement $\mathrm{Nr}$. 5, which is the contradiction of statement Nr. 4. Majority of respondents still believe that involving people who can collect and interpret data is beneficial for this process. Breaking down this result, micro organizations give $60.0 \%$, small organizations give $64.3 \%$, medium organizations give $62.5 \%$, and big organizations give $90.0 \%$.

Statement Nr. 15 at Table 5 indicates that strategy and organization's long-term goal are not correlated, therefore a shift of strategy does not necessarily make organization's long term goal to be modified. This is an incorrect statement. The effectiveness of a strategy needs to be measured by long term and short term goal. Hence, if strategy is changed, automatically long term goal need to be changed to follow the new strategy. The majority of respondents $(75$ organizations or $91.5 \%$ ) also disagree with the statement. Breaking down this result, micro organizations give $88.0 \%$, small organizations give $100 \%$, medium organizations give $100 \%$, and big organizations give $90.0 \%$. Statement Nr. 16 is a contradiction with statement $\mathrm{Nr}$. 15, long-term goal need to be adjusted when strategy is modified. Surprisingly, this time only $53.7 \%$ (44 organizations) support the statement. Breaking down this result, micro organizations give $50.0 \%$, small organizations give $50.0 \%$, medium organizations give $75.0 \%$, and big organizations give $60.0 \%$. Overall, this means respondents include Setting Objective as a strategy formulation process and understand the utilization of setting long-term goal.

Statement Nr. 17 at Table 5 indicates that the function of short-term is to measure if the strategy runs effectively or not. The majority of the respondents (77 organizations or 93.9\%) support the statement. Breaking down this result, micro organizations give $98.0 \%$, small organizations give $92.9 \%$, medium organizations give $87.5 \%$, and big organizations give $80.0 \%$. Statement Nr. 18 indicates that when short-term goal is not met, a review to the strategy implementation method should be done earlier rather than jumping to judge the strategy is not effective. The majority of the respondents (62 organizations or $75.6 \%$ ) support the statement. Breaking down this result, micro organizations give $72.0 \%$, small organizations give $85.7 \%$, medium organizations give $75.0 \%$, and big organizations give $80.0 \%$. Overall, this means respondents include Setting Objective as a strategy formulation process and understand the utilization of setting short-term goal

\section{Crafting Strategy}

Table 6 shows the result of the third process: setting objectives. There is a majority number ( 80 organizations or
$97.6 \%$ ) of the 82 organizations that participate in the survey believe that Crafting Strategy should be part of their strategy formulation process. Breaking down this result, micro organizations give $96.0 \%$, small organizations give $100 \%$, medium organizations give $100 \%$, and big organizations give $100 \%$.

Statement Nr. 7 at Table 6 indicates that strategy is best crafted by involving trusted organization members who has the same Vision - Mission and are willing to put extra effort and thought. The majority of the respondents (78 organizations or $95.1 \%$ ) support the statement. Breaking down this result, micro organizations give $92.0 \%$, small organizations give $100 \%$, medium organizations give $100 \%$, and big organizations give $100 \%$. Statement Nr. 8 indicates a confirmation that a strategy should be in line with Vision Mission, therefore, the organization members involved in crafting the strategy should also have the same Vision Mission. The majority of the respondents (71 organizations or $86.6 \%$ ) show consistency by supporting the statement. Breaking down this result, micro organizations give $94.0 \%$, small organizations give $92.9 \%$, medium organizations give $100 \%$, and big organizations give $100 \%$.

Statement Nr. 19 at Table 6 indicates that one of the advantages of crafting a strategy is to differentiate the organization from its competitors. The organization should become a unique organization. The majority of the respondents (70 organizations or $85.4 \%$ ) agree the statement. Breaking down this result, micro organizations give $88.0 \%$, small organizations give $85.7 \%$, medium organizations give $87.5 \%$, and big organizations give $70.0 \%$. Statement Nr. 20 contradicts with statement $\mathrm{Nr}$. 19. It indicates that the colour and shape of organization will come naturally and does not have correlation with strategy. It is an incorrect statement. The majority of respondents (52 organizations or $63.4 \%$ ) disagree with the statement. Breaking down this result, micro organizations give $54.0 \%$, small organizations give $78.6 \%$, medium organizations give $62.5 \%$, and big organizations give $90.0 \%$. Overall, majority respondents include Crafting Strategy as a strategy formulation process and understand the advantage of creating a strategy to differentiate with other organizations.

Statement Nr. 21 at Table 6 indicates that one of the advantages of crafting a strategy is to adapt with external factors. Hence a change of external (and internal) factors will dictate the organization to re-adapt by modifying the strategy. The majority of the respondents (60 organizations or $73.2 \%$ ) agree with the statement. Breaking down this result, micro organizations give $70.0 \%$, small organizations give $78.6 \%$, medium organizations give $62.5 \%$, and big organizations give $90.0 \%$. Statement Nr. 22 indicates that even when there is no change in external and internal factors, a strategy needs to be renewed regularly. This statement is contradictory to statement Nr. 21. Surprisingly, majority of the respondents (62 organizations or $75.6 \%$ ) support the statement. Breaking down this result, micro organizations give $76.0 \%$, small organizations give $71.4 \%$, medium organizations give $75.0 \%$, and big organizations give $80.0 \%$. Hence, respondents are inconsistent in this case. A follow up questionnaire (see Appendix) has been launched to find out why respondents are not consistent. The target for the follow up questionnaire is respondents who give answer "Yes" for both Statement Nr. 21 and Statement Nr. 22. Respondents who answer "No" for 
both statements are only 3 people, therefore, the number is insignificant to explain the reason for inconsistency. From 45 respondents who give a "Yes" for both statements, 21 respondents $(46.6 \%)$ return the follow up questionnaire. 17 respondents $(81.0 \%)$ choose statement (a) which supports Statement Nr. 21. For statement Nr. 22, there are equally high number respondents (10 people and 10 people) who choose Statement (b) and (c). Apparently respondents, in their minds, have modified Statement Nr. 22. They believe that external and internal factors will never be stagnant and they believe that even if the external factors do not change, the existence of competitors (which is actually part of external factors) will dictate strategy to be modified regularly. Hence, understanding the way the respondents define the scope of external factors and the nature of change, majority respondents are consistent by accepting Statement Nr. 21 and rejecting Statement Nr. 22. Overall, majority respondents include Crafting Strategy as a strategy formulation process and understand the advantage of taking an analysis of external and internal factors during the crafting a strategy.

\section{Executing Strategy}

Table 7 shows the result of the fourth process: setting objectives. There is a majority number (71 organizations or $85.6 \%$ ) of the 82 organizations that participate in the survey believe that strategy formulation process should also include Executing Strategy and they also have this process as the part of their strategy formulation process. Breaking down this result, micro organizations give $84.0 \%$, small organizations give $85.7 \%$, medium organizations give $100 \%$, and big organizations give $90.0 \%$.

On a cross-check, Statement Nr. 10 at Table 7 indicates that strategy is best executed by involving and empowering organization members. The majority of the respondents (64 organizations or $78.1 \%$ ) support the statement. Breaking down this result, micro organizations give $74.0 \%$, small organizations give $71.4 \%$, medium organizations give $100 \%$, and big organizations give $90 \%$. In other word, majority respondents include Executing Strategy as a strategy formulation process and understand the advantage of involving and empowering organization members to support strategy execution effectively.

Statement Nr. 23 at Table 7 indicates that one of the functions of strategy is to guide organization more consistently towards the set Vision and Mission. A strategy is like a path toward the dream of the founder (Vision Mission). Updated strategy will avoid the management to take wrong path and go to different destination. This is a correct statement. The majority of the respondents (77 organizations or $93.9 \%$ ) agree with the statement. Breaking down this result, micro organizations give $92.0 \%$, small organizations give $100 \%$, medium organizations give $100 \%$, and big organizations give $90.0 \%$. Statement Nr. 24 indicates that running an organizational needs high flexibility, pop in creativity, and impromptu decision. Management may make decisions and take actions without thinking far if the decisions and actions may have taken different path (astray from the formulated strategy) toward the Vision - Mission. Hence it is an incorrect statement. The majority of the respondents (64 organizations or $78.1 \%$ ) agree with the statement. Breaking down this result, micro organizations give $82.0 \%$, small organizations give $71.4 \%$, medium organizations give $75.0 \%$, and big organizations give $70.0 \%$. Hence, respondents are inconsistent in this case. A follow up questionnaire (see Appendix) has been launched to find out why respondents are not consistent. The target for the follow up questionnaire is respondents who give answer "Yes" for both Statement Nr. 23 and Statement Nr. 24. Respondents who answer "No" for both statements are only 2 people, therefore, the number is insignificant to explain the reason for inconsistency. From 61 respondents who give a "Yes" for both statements, 27 respondents $(44.3 \%)$ return the follow up questionnaire. 18 respondents $(66.7 \%)$ choose statement (b) which supports Statement Nr. 23. For statement Nr. 24, there are 20 respondents who choose Statement (b). Apparently respondents, in their minds, have modified Statement Nr. 24. They believe being creative and flexible is crucial in managing an organization. However, this creativity and flexibility should in the corridor of Vision - Mission, which rejects Statement Nr. 24. Hence, understanding the way the respondents define the context of flexibility and creativity, majority respondents are consistent by accepting Statement Nr. 23 and rejecting Statement Nr. 24. Overall, majority respondents include Executing Strategy as a strategy formulation process and understand the advantage of having as a route path toward reaching Vision - Mission.

\section{Monitoring Strategy}

Table 8 shows the result of the fifth process: monitoring objectives. There is a majority number (71 organizations or $85.6 \%$ ) of the 82 organizations that participate in the survey believe that strategy formulation process should also include Monitoring Strategy and they also have this process as the part of their strategy formulation process. Breaking down this result, micro organizations give $82.0 \%$, small organizations give $85.7 \%$, medium organizations give $100 \%$, and big organizations give $100 \%$.

On a cross-check, Statement Nr. 12 at Table 8 indicates that strategy is best monitored on a fixed period of time. The majority of the respondents (62 organizations or $75.6 \%$ ) support the statement. Breaking down this result, micro organizations give $72.0 \%$, small organizations give $78.6 \%$, medium organizations give $87.5 \%$, and big organizations give $80 \%$. In other word, majority respondents include Monitoring Strategy as a strategy formulation process and understand the advantage of having a fixed period of time to monitor the effectiveness of a strategy.

Statement Nr. 25 at Table 8 indicates that the effectiveness of strategy needs to be reviewed regularly. A strategy may lose its effectiveness due to various reasons. Therefore, it is recommended to review strategy regularly to maintain its effectiveness. It is a correct statement. The majority of the respondents (79 organizations or 96.3\%) support the statement. Breaking down this result, micro organizations give $98.0 \%$, small organizations give $100 \%$, medium organizations give $87.5 \%$, and big organizations give $90.0 \%$. Statement Nr. 26 indicates that well thought strategy does not need to be monitored regularly. In other words, a well thought strategy will not lose its effectiveness over time. This is an incorrect statement. The majority of the respondents (62 organizations or $75.6 \%$ ) disagree with the statement. Breaking down this result, micro organizations give $66.0 \%$, 
small organizations give $92.9 \%$, medium organizations give $100 \%$, and big organizations give $80.0 \%$. Overall, majority respondents include Monitoring Strategy as a strategy formulation process and understand the advantage of regularly monitor a strategy to check its effectiveness.

TABLE VII: EXECUTING STRATEGY

\begin{tabular}{|c|c|c|c|c|c|c|c|c|c|c|c|c|c|c|c|c|c|c|c|c|c|}
\hline \multirow{3}{*}{ No } & \multirow{3}{*}{ Statement } & \multicolumn{4}{|c|}{ TOTAL } & \multicolumn{4}{|c|}{ MICRO } & \multicolumn{4}{|c|}{ SMALL } & \multicolumn{4}{|c|}{ MEDIUM } & \multicolumn{4}{|c|}{ BIG } \\
\hline & & \multicolumn{2}{|c|}{ YES } & \multicolumn{2}{|c|}{ No } & \multicolumn{2}{|c|}{ YES } & \multicolumn{2}{|c|}{ No } & \multicolumn{2}{|c|}{ YES } & \multicolumn{2}{|c|}{ No } & \multicolumn{2}{|c|}{ YES } & \multicolumn{2}{|c|}{ No } & \multicolumn{2}{|c|}{ YES } & \multicolumn{2}{|c|}{ No } \\
\hline & & $\mathbf{F}$ & $\%$ & $\mathbf{F}$ & $\%$ & $\mathbf{F}$ & $\%$ & $\mathbf{F}$ & $\%$ & $\mathbf{F}$ & $\%$ & $\mathbf{F}$ & $\%$ & $\mathbf{F}$ & $\%$ & $\mathbf{F}$ & $\%$ & $\mathbf{F}$ & $\%$ & $\mathbf{F}$ & $\%$ \\
\hline 9 & $\begin{array}{l}\text { Do you have the process of Executing } \\
\text { Strategy in your organization? }\end{array}$ & 71 & 86.6 & 11 & 13.4 & 42 & 84.0 & 8 & 16.0 & 12 & 85.7 & 2 & 14.3 & 8 & 100 & 0 & 0.0 & 9 & 90.0 & 1 & 10.0 \\
\hline 10 & $\begin{array}{l}\text { Executing strategy needs to involve } \\
\text { and empower people in the } \\
\text { organization }\end{array}$ & 64 & 78.1 & 18 & 21.9 & 37 & 74.0 & 13 & 26.0 & 10 & 71.4 & 4 & 28.6 & 8 & 100 & 0 & 0.0 & 9 & 90.0 & 1 & 10.0 \\
\hline 23 & $\begin{array}{l}\text { Strategy will guide organization more } \\
\text { consistently towards the set Vision } \\
\text { and Mission }\end{array}$ & 77 & 93.9 & 5 & 6.1 & 46 & 92.0 & 4 & 8.0 & 14 & 100 & 0 & 0.0 & 8 & 100 & 0 & 0.0 & 9 & 90.0 & 1 & 10.0 \\
\hline 24 & $\begin{array}{l}\text { Rumning an organizational needs high } \\
\text { flexibility, pop in creativity, and } \\
\text { impromptu decision. }\end{array}$ & 64 & 78.1 & 18 & 21.9 & 41 & 82.0 & 9 & 18.0 & 10 & 71.4 & 4 & 28.6 & 6 & 75.0 & 2 & 25.0 & 7 & 70.0 & 3 & 30.0 \\
\hline
\end{tabular}

TABLE VIII: MONITORING STRATEGY

\begin{tabular}{|c|c|c|c|c|c|c|c|c|c|c|c|c|c|c|c|c|c|c|c|c|c|}
\hline \multirow{3}{*}{ No } & \multirow{3}{*}{ Statement } & \multicolumn{4}{|c|}{ TOTAL } & \multicolumn{4}{|c|}{ MICRO } & \multicolumn{4}{|c|}{ SMALL } & \multicolumn{4}{|c|}{ MEDIUM } & \multicolumn{4}{|c|}{ BIG } \\
\hline & & \multicolumn{2}{|c|}{ YES } & \multicolumn{2}{|c|}{ No } & \multicolumn{2}{|c|}{ YES } & \multicolumn{2}{|c|}{ No } & \multicolumn{2}{|c|}{ YES } & \multicolumn{2}{|c|}{ no } & \multicolumn{2}{|c|}{ YES } & \multicolumn{2}{|c|}{ No } & \multicolumn{2}{|c|}{ YES } & \multicolumn{2}{|c|}{ No } \\
\hline & & $\mathbf{F}$ & $\%$ & $\mathbf{F}$ & $\%$ & $\mathbf{F}$ & $\%$ & $\mathbf{F}$ & $\%$ & $\mathbf{F}$ & $\%$ & $\mathbf{F}$ & $\%$ & $\mathbf{F}$ & $\%$ & $\mathbf{F}$ & $\%$ & $\mathbf{F}$ & $\%$ & $\mathbf{F}$ & $\%$ \\
\hline 11 & $\begin{array}{l}\text { Do you have the process of Monitoring } \\
\text { Strategy in your organization? }\end{array}$ & 71 & 86.6 & 11 & 13.4 & 41 & 82.0 & 9 & 18.0 & 12 & 85.7 & 2 & 14.3 & 8 & 100 & 0 & 0.0 & 10 & 100 & 0 & 0.0 \\
\hline 12 & $\begin{array}{l}\text { Monitoring a strategy need to be done on } \\
\text { a fixed time period }\end{array}$ & 62 & 75.6 & 20 & 24.4 & 36 & 72.0 & 14 & 28.0 & 11 & 78.6 & 3 & 21.4 & 7 & 87.5 & 1 & 12.5 & 8 & 80.0 & 2 & 20.0 \\
\hline 25 & $\begin{array}{l}\text { The effectiveness of strategy need to be } \\
\text { reviewed regularly }\end{array}$ & 79 & 96.3 & 3 & 3.7 & 49 & 98.0 & 1 & 2.0 & 14 & 100 & 0 & 0.0 & 7 & 87.5 & 1 & 12.5 & 9 & 90.0 & 1 & 10.0 \\
\hline 26 & $\begin{array}{l}\text { Well thought strategy does not need to be } \\
\text { monitored regularly }\end{array}$ & 20 & 24.4 & 62 & 75.6 & 17 & 34.0 & 33 & 66.0 & 1 & 7.14 & 13 & 92.9 & 0 & 0.0 & 8 & 100 & 2 & 20.0 & 8 & 80.0 \\
\hline
\end{tabular}

\section{CONCLUSION}

There are no differences between theory and practice in business organizations in Indonesia when formulating strategies. As previously explained, there are 5 stages that were analyzed in this study in formulating this strategy, starting with developing vision-mission, setting objectives, crafting strategy, executing strategy and monitoring strategy. It can be concluded that in micro, small, medium, and big organizations, making a vision and mission is something that must and is generally done. Vision and mission are seen as important to maintain business continuity, and each organization also feels the need to have an aspiration in the future which will be actualized in the form of the organization's vision and mission. Each of these organizations also agrees with the theory that strategy formulation will anticipate changes that occur in both the internal and external environments. As we all know that environmental conditions are unpredictable, because no business is static but all businesses are dynamic. Therefore, changes in economic, political, socio-cultural conditions must be anticipated by each organization to be sustainable.

Respondents believe they should be able to utilize the function of strategy embedded in the formulation processes. Confirmation statement show respondents are consistent in viewing the advantage of function of the strategy. There are no differences among micro, small, medium, and big organizations in regards of doing better formulation process, better effort invested in the process, or better utilizing the function of strategy. It is natural to question the function of strategy in conditions of uncertainty and ambiguity, because strategies are useless in conditions of uncertainty and ambiguous conditions. As explained in the previous section regarding the core functions of the strategy, it is important to see what strategy should be implemented and evaluate whether the strategy is still relevant today. From the results of the respondents' answers, it can be seen that the function of strategy should be able to prepare the organization for the future, be able to find ways to differentiate itself from competitors, can form stability to defend itself, can create harmony between guidelines and actions that must be taken within the organization.

There are still limitations in this study, which come from within the researcher as well as limitations beyond the control of the researcher. Researchers cannot measure the effect of non-response bias on the answers given by respondents. Another limitation, the researcher only applies the survey method through a questionnaire and does not conduct interviews so that the conclusions taken are only based on the data collected through the use of instruments with google forms. The results of this study are expected to encourage further research by adding other variables that can improve the field of strategic management.

\section{APPENDIX \\ FOLLOW UP QUESTIONNAIRE}

Statement Nr.21

When a change in external factor exists, then a strategy needs to be changed

You answered "Yes" to statement Nr. 21 above. Allow us to explore the reasons you answer "Yes":

a) Strategy must adapt to changes in external factors that are outside the organization. 
b) Every time I hear an external factor, I automatically think the strategy must change

c) Changes in external factors do not always cause the strategy to change

d) I want to change my answer to "No"

\section{Statement Nr.22}

Even when there is no change in external and internal factors, a strategy needs to be renewed regularly.

You answered "Yes" to statement Nr. 22 above. Allow us to explore the reasons you answer "Yes":

a) Every time I hear external factors and internal factors, I automatically think the strategy must change

b) External factors and internal factors will always change, may not be stagnant for a long time.

c) Although external factors and internal factors do not change, the existence of competitors (competitors) will dictate to us to always change the strategy

d) I want to change my answer to "No"

\section{Statement Nr.23}

Strategy will guide organization more consistently towards the set Vision and Mission

You answered "Yes" to statement Nr. 23 above. Allow us to explore the reasons you answer "Yes":

a) Decisions made instantly will guard the organization's direction towards Vision - Mission.

b) Strategy is the path that needs to be followed in order to achieve the Vision - Mission. Do not walk outside the groove that has been made

c) Existence of Vision - Mission will automatically stabilize the running of the organization

d) I want to change my answer to "No"

\section{Statement Nr.24}

Running an organizational needs high flexibility, pop in creativity, and impromptu decision.

You answered "Yes" to statement Nr. 24 above. Allow us to explore the reasons you answer "Yes":

a) Decision making as soon as possible is important, don't think too much about other factors.

b) Flexibility and creativity must be in tune with the strategy and Vision - Mission that has been set.

c) If a decision is made because the flexibility demands deviate from the Vision - Mission, the Vision - Mission will be changed to adjust.

d) I want to change my answer to "No"

\section{REFERENCES}

[1] R. Geel, Strategic Management: The Radical Revolutionary Strategic Management Matrix for Predator, USA: Trafford Publishing, 2011, ch.1.

[2] A.W. Steiss, Strategic Management for Public and Nonprofit Organizations (Public Administration and Public Policy), 1st ed. USA Routledge, ch.3.

[3] M.J. Fagel, Principles of Emergency Management: Hazard Specific Issues and Mitigation Strategies, 1st ed., NewYork: CRC Press, 2012, ch. 4 , pp. 69.

[4] M. Preedy, R. Glatter, and C. Wise, Strategic Leadership and Educational Improvement. London: Paul Chapman Publishing,2003, ch.10, pp.106.

[5] S. Crainer and D. Dearlove, Financial Times Handbook of Management, 3rd ed., UK: Pearson Education Limited, ch.6.

[6] R. L. Daft, Management. USA: Cengage Learning, 2012, ch.8., pp. 224
[7] F. Voehl and H.J. Harrington, Change Management: Manage the Change or It Will Manage You. USA: Taylor \& Francis Group,LLC, 2016, ch.3., pp.37.

[8] J.O. Ogbor, Entrepreneurship in Sub-Saharan Africa: A Strategic Management Perspective. USA: AuthorHouse,2009, ch.6., pp. 290.

[9] A. Kusumapriandana, Rahasia Strategi Bisnis Kreatif Infia di Tengah Krisis COVID-19, 2020, https://www.jurnal.id/id/blog/rahasiastrategi-bisnis-kreatif-infia-di-tengah-krisis-covid-19/

[10] G. Undarsa, Sektor Perjalanan Dihantam Corona, Begini Strateg Tiket.comBertahan,2020,https://teknologi.bisnis.com/read/20200413/ 266/1226444/sektor-perjalanan-dihantam-corona-begini-strategitiket.com-bertahan.

[11] V.Y. Sinaga, Bisnis Dihantam Corona, Ini Strategi AirAsia Demi Bertahan,2020,https://www.cnbcindonesia.com/market/20200504162 333-17-156135/bisnis-dihantam-corona-ini-strategi-airasia-demibertahan

[12] F.G. Boseman and A.V. Phatak, Cases in Strategic Management. US: Wiley, 1998, ch.1.

[13] D. Campbell, D. Edgar and G. Stonehouse, Business Strategy: An Introduction, 3rd ed, Red Globe Press, 2011, ch.1.

[14] E. Stephens, and B. Martin, Business Policy and Strategic Management, 1st ed., UK: ED-TECH PRESS, 2019, ch.3.

[15] J.H. Trivedi, Fundamentals of Strategic Planning and Development, India: RED'SHINE Publication. Pvt. Ltd., 2019, ch.1.

[16] A. Annarelli, C. Battistella, and F. Nonino, The Road to Servitization: How Product Service Systems Can Disrupt Companies' Business Models. In The Road to Servitization., 2019 , https://doi.org/10.1007/978-3-030-12251-5, ch.4.

[17] A.A. Thompson, M.A. Peteraf, J.E. Gamble and A.J. Strickland, Crafting and Executing Strategy: The Quest For Competitive Advantage. New York: McGraw-Hill Education, 2014, ch.2.

[18] J. Aurik, M. Fabel, and G. Jonk, The future of strategy: a transformative approach to strategy for a world that won't stand still. NY: McGraw-Hill Education, 2014, pp. 192

[19] J. Kraaijenbrink, The Six Functions Of Strategy. https://www.forbes.com/sites/jeroenkraaijenbrink/2019/01/08/the-sixfunctions-of-strategy/\#6a338d6d57b9, 2019.

[20] U. Sekaran, and R. Bougie, Research Methods for Business: A Skill. Building Approach. New York: John Wiley \& Sons, 2013, ch.3.

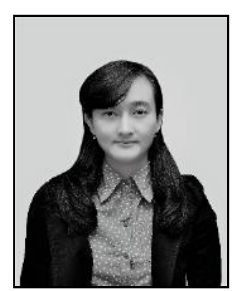

Rapina Rapina earned her undergraduate degree (Majoring in Accounting) from Maranatha Christian University, Indonesia in 2007. She continued her study at Padjadjaran University, Indonesia in 2006 to get Magister Science degree and get his doctorate degree from Padjadjaran University, Indonesia in 2017. Rapina Rapina is currently a lecturer at Maranatha Christian University (Head of Graduate Program in Accounting), Indonesia.

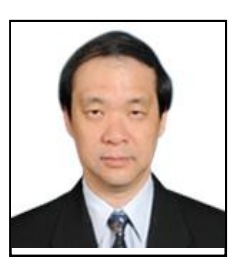

Johannes Buntoro Darmasetiawan earned his undergraduate degree (Majoring in Civil Engineering) from Parahyangan Catholic University, Indonesia in 1994. He continued his study at Case Western Reserve University in 1986 to get Master of Science in Civil Engineering degree, in 1986 at Baldwin Wallace College to get Master of Business Administration, in 1993 at Antioch University to get Master of Arts and get his doctorate degree from SAIDI School of Organization Development in 2003. Johannes Buntoro Darmasetiawan is currently a lecturer at Maranatha Christian University, Indonesia and at SAIDI School of Organization Development, Phillipines. Johannes is also the chairman of PT. Gistex Garmen Indonesia. PT. Gistex Garmen Indonesia is one of the leading garment manufacturer in Indonesia.

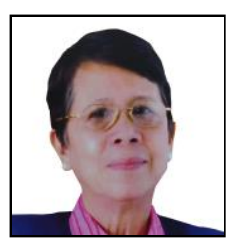

Rosalina O.Fuentes earned her Doctor of Philosophy in Organization Development from the Southeast Asia Interdisciplinary Development Institute (SAIDI), her Master of Arts in Education with specialization in Curriculum Development and Instructional Planning from the University of Nueva Caceres, and her Bachelor of Arts and Science in Education major in History from the Ateneo de Naga. She continues to $\backslash$ "sharpen the saw $\backslash$ " with her post-doctoral certification in Organization Development from Stanford University, trained by David Cooperrider in Appreciative Inquiry at Case Western Reserve in Taos, New Mexico, trained in Governance and Risk Management (Banking Sector) by the Rural Bank 
Association of the Philippines, earned her certification in TESOL at the University of Manoa-Hawaii (USA), ELT certification from the University of Reading, London (UK) and Train the Trainors certification from the same university. She was the President of SAIDI Foundation, a position she assumed in January 2010.

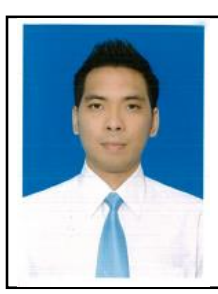

Duarte Davinci Doloksaribu earned his undergraduate degree (Majoring in Accounting) from Bandung Adventist University, Indonesia in 2010 Currently he is pursuing his master's degree in Master of Accounting, at Maranatha Christian University Bandung. He worked as an accountant at a multinational company in 2010, worked as an accountant at local coal mining Company in 2012, and as finance at multinational company in 2018 .

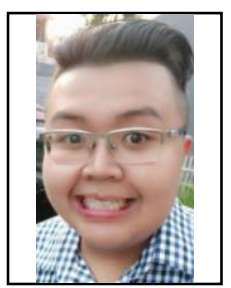

Recky Noviansyah earned his undergraduate degree (Majoring in Management) from Parahyangan Catholic University, Indonesia in 2017. Currently he is pursuing his master's degree in Master of Accounting, at Maranatha Christian University Bandung, Indonesia 